\title{
Basics of Binocular Single Vision and Strabismus
}

\section{Dr Partha Haradhan Chowdhury ${ }^{1 *}$ and Brinda Haren Shah ${ }^{2}$}

${ }^{1}$ Ph.D. in Optometry (Gujarat State Government University) and Professor and

Principal, Shree Satchandi Jankalyan Samiti Eye Institute - Pauri, Uttarakhand, India

${ }^{2}$ M. OPTOM, Practitioner, Ahmedabad, Gujarat, India

*Corresponding Author: Dr Partha Haradhan Chowdhury, Ph.D. in Optometry (Gujarat State Government University) and Professor and Principal, Shree Satchandi Jankalyan Samiti Eye Institute - Pauri, Uttarakhand, India.
Received: March 23, 2021

Published: April 10, 2021

(C) All rights are reserved by Dr Partha Haradhan Chowdhury and Brinda Haren Shah.

\section{Abstract}

This paper describes about Basic information of Binocular Single Vision and Strabismus.

Keywords: Binocular Single Vision; Strabismus; Retinal point

\section{Introduction}

Binocular single vision is a condition where one eye retinal point is properly coordinated to another eye. Another name of the retinal point is retinal corresponding point. It indicates that proper retinal stimulation comes from the brain to the visual cortex. In case of binocular single vision, fovea of both the eyes are corelated properly.

Binocular single vision consists of 3 grades:

- Simultaneous macular perception

- Fusion

- $\quad$ Stereopsis.

It should be always remembered that when binocular single vision is maintained properly, then normal retinal correspondence is also maintained. It stimulates properly to "cortical process". It mainly occurs due to binocular fusion.

Binocular fusion is maintained by:
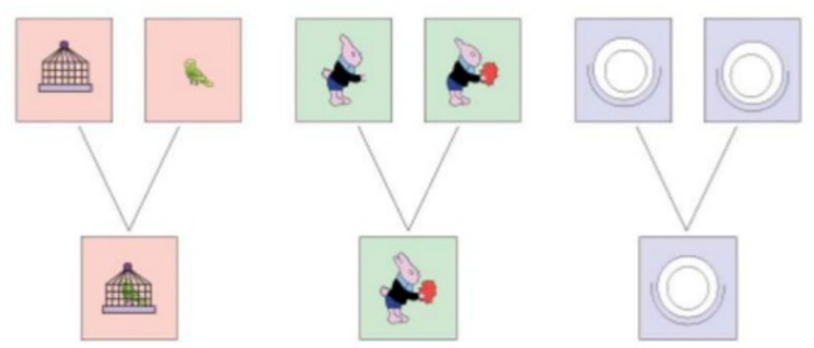

Figure 1
- Sensory fusion

- Motor fusion.

\section{Sensory fusion}

It is a cortical process, it means whatever the stimulation comes from the retina to the brain, that creates proper image. If any type of anomaly is found in the cortical process, then patient can get problem in sensory fusion. 


\section{Motor fusion}

Motor fusion means, by the ocular movement eye will be fused properly to an object. If any type of anomalies found in the extra ocular movement, then motor fusion is hampered.

In case of binocular single vision, two terms are very important for it.

- Horopter

- Panum's fusional area.

\section{Horopter}

Horopter is a particular area which is away from the observer, sharpest images are created to the observer.

\section{Panum's fusional area}

It is a particular area, in front and behind the Horopter where images are seen properly. It is narrow centrally and broader peripherally.

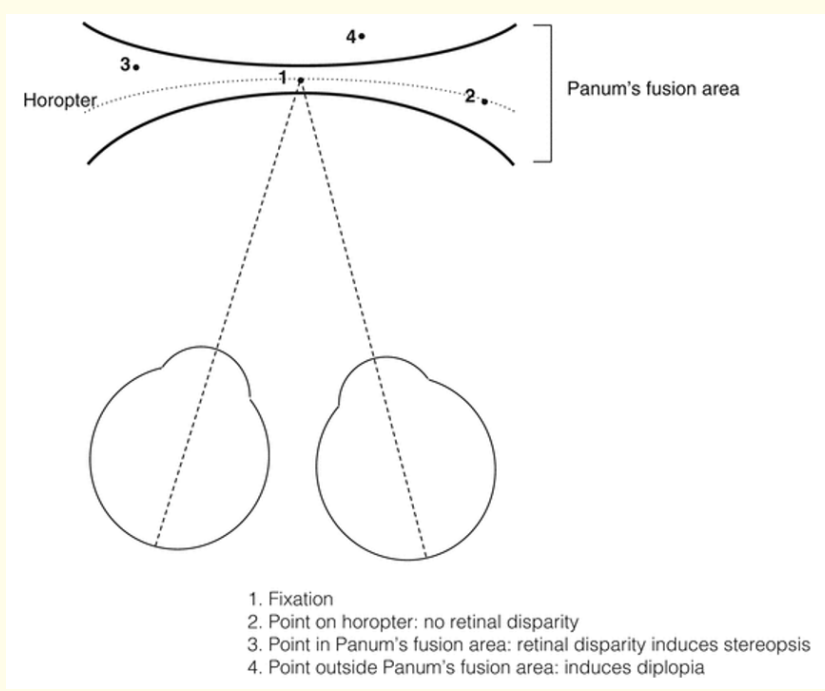

Figure 2

Always it is remembered that binocular single vision is measured by synaptophore.

It is acceptable that stereopsis is always associated with 3-dimensional object because it can stimulate non-corresponding point. Stereopsis may be associated with two-dimensional object, if two eyes see same object and if horizontal offset is found.

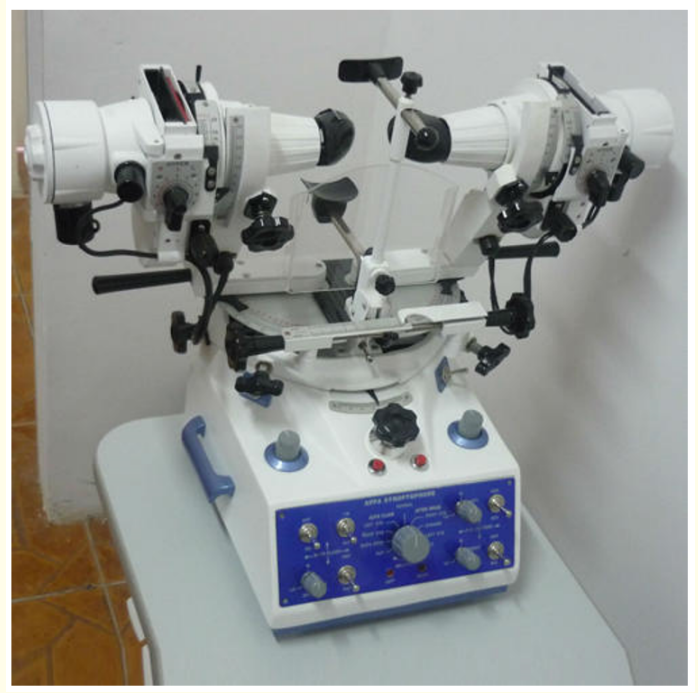

Figure 3

Binocular single vision is hampered during ocular deviation. When eye is misaligning from its primary position then it is called squint.

When eye is in latent position means fusion break and eye is deviated then it is called phoria. When always eye is deviated it is called tropia.

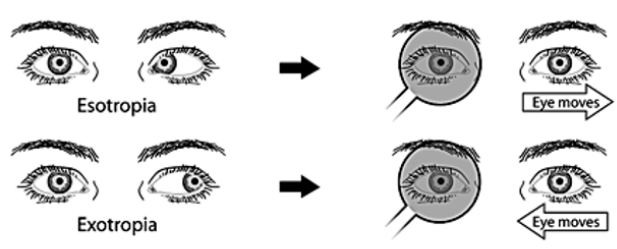

Cover - Uncover tests

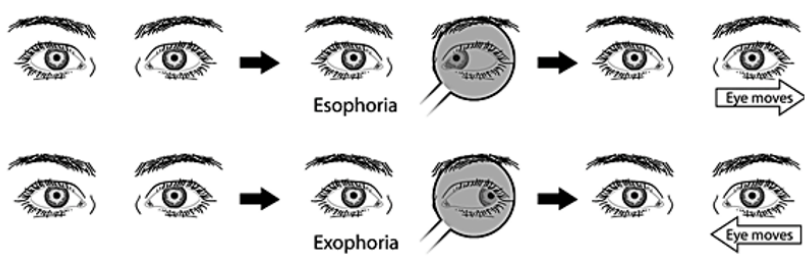

Figure 4 
When eye is deviated then images are fallen from the foveal area to the parafoveal region which hampers binocular single vision.

In case of exo deviation images fall on the temporal fovea and in eso deviation images fall on the nasal fovea.

Esodeviation creates more amblyopia as compared to exo deviation due to fusional vergence. In case of eso deviation amplitude of fusional vergence of treatment is less as compared to exo deviation.

Usually, eso deviation is treated with cycloplegic refraction or plus lens or with base in prism.

Eso Deviation is treated with Base Out Prism and Exo Deviation is treated with Base In Prism. [1-4].

\section{Bibliography}

1. Kenneth W Wright. "Handbook of Pediatric Strabismus and Amblyopia”. $2^{\text {nd }}$ (Edition) (2006).

2. William J Benjamin. "Borish's Clinical Refraction $2^{\text {nd }}($ Edition)" (2006).

3. Theodore Grosvenor and Theodore P Grosvenor. "Primary Care Optometry". $5^{\text {th }}$ (Edition) (2007).

4. Sir Stewart Duke-Elder and David Abrams. "Duke Elder's Practice of refraction" (1978).

\section{Assets from publication with us}

- Prompt Acknowledgement after receiving the article

- Thorough Double blinded peer review

- Rapid Publication

- Issue of Publication Certificate

- High visibility of your Published work

Website: www.actascientific.com/

Submit Article: www.actascientific.com/submission.php

Email us: editor@actascientific.com

Contact us: +919182824667 